Check for updates

1 Liverpool Hospital in Sydney

2 School of Public Health, University of Sydney

3 Department of Epidemiology and Preventive Medicine, Monash University

4 Monash-Cabrini Department of Musculoskeletal Health and Clinical Epidemiology, Cabrini Health

Cite this as: BMJ 2021;375:n2807 http://dx.doi.org/10.1136/bmj.n2807 Published: 16 November 2021

\section{How doctors are betraying the Hippocratic oath}

\author{
Ian A Harris, 1,2 Rachelle Buchbinder ${ }^{3,4}$
}

There are many respects in which the modern medical system is not fit for purpose and poses a threat to human health. In so many situations, our superficial assumptions about medicine are wrong. Having more tests to identify disease is often not better than leaving those "well enough" alone, labelling people with a specific disease may not be helpful, and more medicine may not be better than less medicine or no medicine at all. ${ }^{1}$ In our eagerness to intervene, we can end up doing harm. This fits with the estimation that around $30 \%$ of medical care is ineffective and another $10 \%$ is harmful. ${ }^{2-4}$

The common modern version of the Hippocratic Oath points to many of these problems. Quotes from the pledges and the problems they highlight include:

- "I will respect ... scientific gains"-poor science literacy and the belief in personal experience over scientific evidence;

- “avoiding ... overtreatment”-overtreatment and overdiagnosis;

- "warmth, sympathy and understanding may outweigh the surgeon's knife or the chemist's drug"-reliance on medical intervention over natural history and reassurance;

- "responsibility must be faced with humbleness"-doctors' overestimation of medical effectiveness;

- "I do not treat a fever chart ... but a sick human being"- the treatment of risk factors and surrogate outcomes; and

- "prevention is preferable to cure"-reliance on often expensive and harmful interventions over public health measures that may prevent a condition.

Unnecessary imaging, opioids, and surgery for non-serious back pain; arthroscopic surgery for knee osteoarthritis; subacromial decompression for shoulder pain; platelet-rich plasma injections for tendinopathies and osteoarthritis; vertebroplasty for acute spinal fractures; and diagnosing and treating "pre-osteoporosis" exemplify some of the problems rife within our field of medicine alone. But other medical fields have not escaped criticism for overdiagnosis and overtreatment either. Examples include cardiac stenting for stable angina, prostate specific antigen screening for prostate cancer, and overtreatment in end-of-life care. ${ }^{1}$ But why do doctors recommend tests, or diagnose and prescribe treatments that don't help people?

Our observation is that doctors are not very different to practitioners of the many alternatives to medicine: they are reluctant to admit that they don't know, and they see not testing or treating a patient as a "failure" to care. There is an expectation on both sides-from the patient and the doctor-to exclude or provide a diagnosis and treatment. This leads to defensive medicine, a tendency to create diagnoses and diseases, to treat numbers or other surrogates regardless of symptoms (the "normalisation heuristic"), and to "try" a treatment rather than opting for reassurance, advice, and careful waiting. ${ }^{5}$

These decisions are based on a distortion of the risks and benefits of treatments for individual patients, which arise from doctors' consistent overestimation of the benefits of treatments and an underestimation of the harms. ${ }^{6}$ A common cause of this problem is a lack of understanding of the science of medicine. This allows a form of medical exceptionalism to exist, whereby some doctors do not consider evidence that was derived from other practitioners and regions to apply to them or their patients. They will believe their own observations and thus research that suits their prior beliefs, but reject contradictory less-biased research. ${ }^{7}$

Often, contempt for good evidence also spills over into personal assaults towards the producers of that evidence. Bullying and intimidation is almost routine now for researchers and doctors who expose the flaws in our thinking and who advocate for evidence-informed medicine. This is illustrated most recently by the attacks on epidemiologists who comment publicly on covid-related matters. ${ }^{9}$

Doctors are the gatekeepers of healthcare, yet are rarely identified as a cause of its problems alongside the system itself and industry. But while perverse incentives in the system and pressure from industry can drive bad practices, in the end it is the doctors who are voluntarily requesting the tests, writing the prescriptions, and performing the surgery. The harms of modern medicine are being increasingly recognised by journals (e.g., The BMJ's Too Much Medicine series), professional societies (eg, the worldwide Choosing Wisely initiative), and researchers (e.g., the Australian Wiser Healthcare collaboration). ${ }^{10}{ }^{11}$ Yet, if we are to address the causes of harmful, wasteful, and ineffective practice in medicine, we must involve those who are making and guiding the decisions: the doctors themselves.

Doctors need to understand that their personal biases and lack of scientific rigour is contributing to the waste and harms of modern medicine and diverting resources away from the delivery of effective care. No single solution will work in isolation, but we all need to start asking questions that challenge the status quo. Those with the power also need to address the perverse incentives and vested interests inherent in a system that promotes more medicine.

As a matter of urgency, these issues also need to be aired with our patients and communicated to the public. Some may ask whether we should be 
questioning the medical establishment during a pandemic. But if the harms that are being caused by the proliferation of misinformation about covid-19, including by doctors, has taught us anything, it is that we cannot afford to wait a minute longer to bring attention to harmful and wasteful practices.

Competing interests: none declared

Provenance and peer review: commissioned, not peer reviewed

1 Buchbinder R, Harris I. Hippocrasy: how doctors are betraying their oath. New South, 2021.

2 Brownlee S, Chalkidou K, Doust J, etal. Evidence for overuse of medical services around the world. Lancet 2017;390:156-68. doi: 10.1016/S0140-6736(16)32585-5 pmid: 28077234

3 Kohn LT, Corrigan JM, Donaldson MS. To err is human: building a safer health system. Institute of Medicine, 1999.

4 Slawomirski L, Auraaen A, Klazinga NS. The economics of patient safety, in OECD Health Working Papers. 2017.

5 Aberegg SK, O’Brien JMJr. The normalization heuristic: an untested hypothesis that may misguide medical decisions. Med Hypotheses 2009:72:745-8 doi: 10.1016/j.mehy.2008.10.030 pmid: 19231086

6 Hoffmann TC, Del Mar C. Clinicians' expectations of the benefits and harms of treatments, screening, and tests: A systematic review. JAMA Intern Med 2017;177:407-19. doi: 10.1001/jamainternmed.2016.8254 pmid: 28097303

7 Doherty TS, Carroll AE. Believing in overcoming cognitive biases. AMA J Ethics 2020;22:E773-8 doi: 10.1001/amajethics.2020.773 pmid: 33009773

8 Saposnik G, Redelmeier D, Ruff CC, Tobler PN. Cognitive biases associated with medical decisions: a systematic review. BMC Med Inform Decis Mak2016;16:138. doi: 10.1186/s12911-016-0377-1 pmid: 27809908

9 Nogrady B. 'I hope you die’' how the COVID pandemic unleashed attacks on scientists. Nature 2021;598:250-3. doi: 10.1038/d41586-021-02741-x pmid: 34645996

10 ABIM Foundation (American Board of Internal Medicine). ACP-ASIM Foundation (American College of Physicians-American Society of Internal Medicine), European Federation of Internal Medicine. Medical professionalism in the new millennium: a physician charter. Ann Intern Med 2002;136:243-6.

11 Moynihan R, Barratt AL, Buchbinder R, etal. Australia is responding to the complex challenge of overdiagnosis. Med J Aust 2018;209:332-4. doi: 10.5694/mja17.01138 pmid: 30309305 